\title{
Microscopic Study of Oculomotor Nucleus in Human Adult
}

\author{
II Report \\ By \\ Saiyo Atsuki \\ (厚木溜陽) \\ From the Anatomical Laboratory of Prof. H. Seto, \\ Tohoku University, Sendai
}

(Received for publication, February 3, 1953)

I have reported in the previous number of this series of reports on the minute structure of the nerve cells in the various parts of oculomotor nucleus in human adult ${ }^{11}$. In this report, I will detail the external nerve fibres, the intranuclear nerve plexus and the oculomotor nerve root conerned with the oculomotor nucleus.

A. External nerves

Entrance of motor nerve fibres from the tractus corticobulbaris of tractus pyramidalis as well as sensory nerve fibres connected with the ocular reflex into the oculomotor nucleus must be expected, as in all other cerebrospinal motor nuclei, but the routes of such incoming nerve fibres have remained very obscure to date. In particular, the course of the motor nerve fibres have never been exhaustively inquired into.

According to my observations, the motor nerve fibres seem to be represented by a number of nerve fibres originating in the tractus pyramidalis cruris cerebri, running along the rhaphe with or without crossing and reaching the chief and median nuclei of oculomotor nucleus, while the sensory nerve fibres are represented by the partially intercrossing thick fibres originating in the stratum griseum centrale, and the strongly staining thick fibres running longitudinally through the chief nucleus, but I feel some incertitude on the accuracy of the above description.

Thus I failed to make a satisfactorily clear observation on the ending formation in the oculomotor nucleus of the incoming motor and sensory fibres, but I could neither observe any of the extremely simple and rough reticular terminations around the cells, nor the neural connection of the external nerve fibres and the nerve cells. On the contrary, the incoming nerve fibres appear to branch or anastomose in the neuroglia tissue and make the transition into the intranuclear plexus described hereunder. Consequently, the transmission of impulses to the oculomotor nucleus, 
similar to the cortex cerebelli (Yamamoto $\left.{ }^{2}\right)$ and to the nucleus nervi hypoglossi $\left(\mathrm{Sato}^{3)}\right)$ seems to be effected by the stimuli coming over the external nerve fibres exciting the neuroglia tissue which is probably endocrine in nature, the endocrinal secretion serving to excite the nerve cells and their short processes secondarily, the stimulation being then transmitted peripherally through the long processes.

B. Intranuclear nerve plexus

The nerve cells in the oculomotor nucleus, together with their processes, are buried in a system of complex nerve plexus, but the nature of this plexus has never been histologically elucidated. According to what I have observed in my study, this plexus is a very complex formation composed of incoming motor, sensory and vegetative nerve fibres around the various nerve cells and their processes in the oculomotor nucleus. However, I failed in exposing the details of the terminal formation of the various kinds of nerve fibres. For example, it was sometimes impossible to decide whether the terminal branches of these fibres end freely or in reticular formation. But it is beyond doubt that the figures of strongly staining thick fibres and their sections represent motor and sensory nerve fibres, and the minute fibres arranged reticularly derive from incoming vegetative nerve fibres. and 2)

C. Oculomotor nerve root, especially, decussating fibres (Figs. 1

Fig. 1

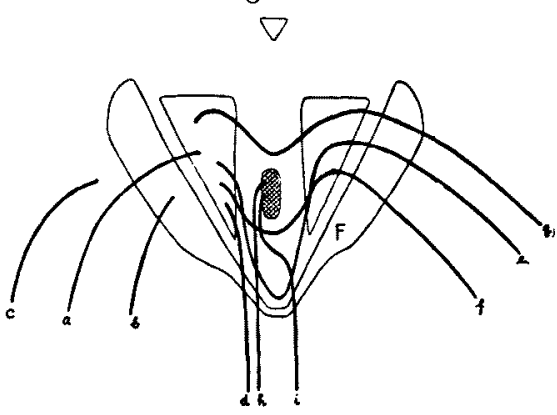

Fig. 2

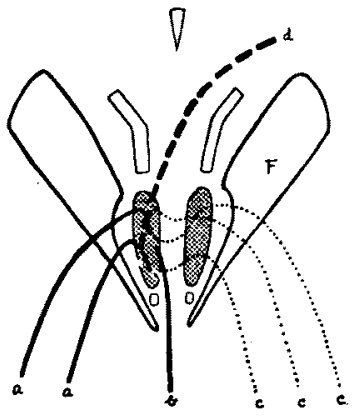

Fig. 1. Schema of course of motor fibres from the motor nuclei of oculomotor nucleus in man. Horizontal section at the level of the lower part. $a, b, c$ lateral non-decussating fibres, $d$ median non-decussating fibres, and e, $f, g$ decussating fibres from the chief nucleus; $h$ non-decussating fibres and i decussating fibres from the median nucleus; F fasciculus longitudinalis medialis.

Fig. 2. Schema of course of motor nerve fibres from the chief nucleus of oculomotor nucleus in the same section as above. a lateral non-decussating fibres, b median non-decussating fibres and $c$ decussating fibres; d sensory nerve fibres. 
In horizontal sections, the oculomotor root bundle shows in general a characteristic S-formed curve outwardly, after having penetrated the fasciculus longitudinalis medialis, but at the lowermost part, no formation of root bundle is seen. The root fibres run along the base of the nucleus ruber, then through the centre of the nucleus niger. At higher levels, the fibres run along the inner side wall of the nucleus ruber and emerge through the substantia alba near the median line. The root fibres in the topmost part penetrate the substantia alba further adjacent to the rhaphe.

On the decussating fibres in the root bundle opinions are yet divided. First, Gudden ${ }^{4}$ observed partial decussation in vertebrates, and Perlia ${ }^{5}$, Kölliker $^{6 /}$ and van Gehuchten ${ }^{7}$ in man. Kölliker assumed their origin in the outer ventral cell group of the chief nucleus and Perlia and van Gehuchten in the dorsal cell group of it. Obersteiner ${ }^{8)}$ asserted that all decussating fibres originated on the dorsal side only, but Bernheimer" suggested that the lower part of the oculomotor nucleus sends out decussating fibres only, the middle part, decussating as well as non-decussating fibres and the upper part, mainly non-decussating fibres, so decussating fibres come from the dorsal as well as the ventro-caudal sides of the nucleus.

My study showed that decussating fibres greatly predominate in the lower part of oculomotor nucleus, only few non-decussating fibres being found. The decussating fibres originate in circa $2 / 3$ of the dorsal area of the chief nucleus, but a part also comes from $1 / 3$ of its ventral area. The course of these decussating fibres is, first toward the inner ventral part of the same side, then abruptly to the lower caudal part down to the median line a little above the caudal end of the fasciculus longitudinalis medialis and thence, turning in an acute angle, running in a lemniscus up to the opposite side, to penetrate through the chief nucleus on that side and finally enter the fasciculus longitudinalis medialis. In the upper regions, the decussating fibres become extremely small in number, but emerge equally from all sides of the chief nucleus, and attain the opposite side without running any lemniscular course as described above. Also some of the fibres derived from the nucleus medianus seem to decussate.

\section{SUMMARY}

In probability, the motor nerve fibres coming from the tractus pyramidalis cruris cerebri are represented by the nerve fibres running along the rhaphe to the chief and median nuclei after or without decussating, while the sensory nerve fibres are represented by the fibre group coming from the stratum griseum centrale partially decussating and fibres running longitudinally through the chief nucleus, but many points are not yet in the clear on the subject. 
The ending formation of the external motor and sensory nerve fibres in the oculomotor nucleus could not be elucidated satisfactorily, but I certainly could not observe any simple terminal networks around the cells and others as would have been expected according to the Langley's neuron theory. On the contrary, these fibres, after branching and anastomosis in the neuroglia tissue, seem to go over into extremely complex intranuclear plexus found around the nerve cells and their processes. Though many points remain to be clarified regarding the formation of this plexus, it is at least certain that the strongly stainable thick fibres represent motor and sensory nerve elements and the minute fibres showing fine reticular formation, vegetative nerve elements.

The majority of the oculomotor nerve root is composed of decussating fibres at the lower part of the oculomotor nucleus, originating mainly from the dorsal side of the chief nucleus and partly from the ventral side thereof. These head first toward the inner ventral part of the same side, then abruptly drop to a point a little above the lower end of the fasciculus longitudinalis medialis, cross over the median line, return upwards to penetrate the chief nucleus of the opposite side and enter the fasciculus longitudinalis medialis. In the upper part of the nucleus the decussating fibres are found extremely small in number. They emerge from various sides of the chief nucleus and attain the opposite side without running such a devious course. Also some of the median fibres coming from the upper part of the median nucleus apparently decussate in their course.

\section{References}

1) Atsuki, Tohoku J. Exp. Med. in press.

2) Yamamoto, Tohoku Igaku Zassi, 1948, 38, 81.

3) Sato, ibid., 1949, 39, 151.

4) Gudden, Arch. Psych., 1866, 2, 364.

5) Perlia, Neur. Zbl., 1890, 9, 236.

6) Kölliker, Handbuch d. Gewebelehre d. Menschen, Leipzig, W. Engelmann, 1893.

7) Van Gehuchten, Anatomie du systéme nerveux de h'homme, Louvain, A. UystruystDieudonné, 1906.

8) Obersteiner, Anleitung b. Studium d. Baues d. nervösen Zentralorgans, Leipzig, Deuticke, 1912.

9) Bernheimer, Mschr. Psych., 1898, 15, 151. 